\title{
The Prediction of Carbon Dioxide Emission Using ARIMA for Support Green Energy Development in Surabaya Municipality
}

\author{
Juniarko Prananda $^{\text {a*, Ridho Hantoro }}{ }^{\text {a }}$, Gunawan Nugroho ${ }^{\mathrm{a}}$ \\ ${ }^{\mathrm{a}}$ Sepuluh Nopember Institute of Technology, Engineering Physics Dept., Jln Keputih, Sukolilo, Surabaya 60111, Indonesia
}

\begin{abstract}
Surabaya is a metropolitan city in Indonesia. As well as the second largest city in Indonesia, with average yearly GDP growth of Surabaya increased $5 \%$ of the national GDP, Surabaya has attraction for the urbanization and very strategic for the investors to build their industry in Surabaya. This leads to industrial sector, transportation, and the number of civilians growing rapidly which has the impact on the air quality in Surabaya. The most influential of air quality is the emission of $\mathrm{Carbon}^{\mathrm{Dioxide}}\left(\mathrm{CO}_{2}\right)$. Carbon Dioxide is a greenhouse gases that provide the largest contribution to global warming and climate change. This has negative impact to humans, so it is necessary conduct a research on the Carbon Dioxide emission growth being produced from the transportation, the industrial Sector, and household in Surabaya. The purpose of this research is to get prediction model for Carbon Dioxide emission growth being produced in the Surabaya. The prediction model can be represented the carbon Dioxide emissions growth in the next years that would give recommendations to the Surabaya Municipality Government for preventive action to reduce the Carbon Dioxide emission in Surabaya.
\end{abstract}

Keywords: Carbon dioxide; emission; prediction

\section{Introduction}

Climate change has become a subject was warmly to discuss in the last decade ${ }^{[1]}$. A greenhouse gases are the cause of climate change not only come from natural factors but the greenhouse gases also emanated from human activities. Based on the research has been done, we known, Human activities have a significant contribute to increase the concentration of greenhouse gases in the atmosphere. An increase concentration of greenhouse gases in the atmosphere cause the Earth surface temperature higher because get in covered the greenhouse gases in the atmosphere. Even in a research said that the human life has a very significant contribution to the process of global warming $^{[3]}$. Surabaya is a metropolitan city is very strategic for market industries, business, education, and tourism. Because those factors causing Surabaya have special attraction for urbanization from surrounding cities. The high flow urbanization eventually also the public transportation will be increased. Along the increasing population, it will impact on the economy grows with increase in demand for energy. And then, it would cause an increase in the energy emissions from human activity to air especially of motor vehicles. That is a major source of air pollution in

\footnotetext{
* Corresponding author. Tel.: +62 83849988118

E-mail address: juniarko.prananda@gmail.com
} 
Surabaya. The emphasis the level of emissions, it also needs to reduce the carbon dioxide emission. The green open space in Surabaya necessary increase in order to reduce carbon dioxide emission.

Based on Indonesia Government Regulation no 41 / 1999, Air pollution is the entry an astringent, energy and / or other components into the air ambient from human activities so the air ambient level down that causes air ambient unable their functions. Air pollution is one of the main problems that often occur in big cities. The primary cause of these problems is the population growth combined with the changes of land, transportation, Industry and house hold activity $^{[4]}$. Pollutants will spread and mingled in the atmosphere. Pollutants from any source through this process will be spread over the diffusion, the dispersion, and transform chemicals.

\section{Greenhouse gases}

Greenhouse gases are the gases in the atmosphere that cause the greenhouse effect. Greenhouse gases is already existed since the formation of the earth. These gases into the earth surface by any natural process and also due to human activities such as burning fuel oil gas, coal and burning forests. The increase greenhouse gases in the atmosphere will hold a lot of sun radiation so that it will increase the temperature at the surface of the Earth. The greenhouse effect due to an increase in concentration of $\mathrm{CO}_{2}$ and other greenhouse gases in the atmosphere. On the greenhouse effect, energy into the Earth $25 \%$ will be reflected by clouds or other particles in the atmosphere, $25 \%$ absorbed by the clouds, $45 \%$ absorbed by the earth surface and $5 \%$ is reflected back by the Earth surface. The absorption of energy that is reflected back by the earth surface and the cloud in the form intensity of heat (infrared radiation). However, mostly infrared radiation emitted to the Earth surface hampered by the clouds and the greenhouse gases. This, heat energy, can warm up the Earth. So, basically, greenhouse effect needed to keep the temperature of the Earth. Without the greenhouse effect, the temperature at the surface of the Earth shall be too cold and couldn't inhabited. But, the increase of greenhouse gases in the atmosphere will increase the temperature at the surface of the Earth and cause the global warming.

\section{Autoregressive Moving average (ARIMA)}

ARIMA is a method which use the iterative approach for identification models. A model has been chosen tested with a new historical data to see the model has been adequate or not. The model had been adequate if the residual (the difference from the results of forecasting with the data historically) distributed at random, small and independent of each other.

ARIMA can only be implemented in stationary time. firstly, we must check our data whether stationary or not. If our data is not stationary, one thing that can be done is checking in data differentiation that will become stationary, or finding d value. This process can be done by using ACF (Auto Correlation Function), or unit roots test and Integration Degree. If our data is stationary for cascading data, then differentiation is not required and $\mathrm{d}$ value is 0 (zero).

In addition of finding $d$ value, on this step we also find lag residual value (q) and lag dependent value (p) that used in model. Main tools for finding $\mathrm{q}$ and $\mathrm{p}$ is ACF and PACF (Partial Auto Correlation Function) and correlogram that show ACF value plot and PACF towards lag.

Partial Autocorrelation Coefficient measure relation between Xt and Xt-k while time lab effect 1, 2, 3,..,k-1 considered constant. In other word, Partial Autocorrelation Coefficient measure relationship degree between present value with previous value (for certain time lag), while effect of the other variable time lab value considered constant. Mathematically, Partial Autocorrelation Coefficient order is m define as Last Autoregressive Coefficient from model AR(m). 
Table 1. ACF and PACF.

\begin{tabular}{ccc}
\hline Model Type & Typical ACF & Typical PACF \\
\hline AR(p) & Decreasing exponentially to zero & Significant in all lag $\mathrm{p}$ \\
MA(q) & Significant in all lag $\mathrm{p}$ & Decreasing exponentially to zero \\
ARMA(p, q) & Decreasing exponentially to zero & Decreasing exponentially to zero \\
\hline
\end{tabular}

After determine temporary model from identification result, finding $\mathrm{p}, \mathrm{d}$, and $\mathrm{q}$ value, Next step is estimated Autoregressive Parameter and moving average. If pure AR process is identified then parameter can be estimated with Least Square. If a MA pattern is identified then maximum likelihood and Least Square estimation, both need non-linier optimization method and happen because moving average that causing nonlinearity parameter.

A Component that contain of AR and MA is called ARIMA (p, d, g). Time series Model which has been used based on assumption that time series data is stationary, means variant averages $(\sigma 2)$ is constant time series data. But as we know, many time series data in economics is not stationary, but integrated. If time series data is integrated with order 1 called I (1) mean first differencing process. if this series through differencing proses to $d$ times can be made stationary, then this series is called not stationary homogeny $\mathrm{d}$ level.

Often random stationary proses can't be well explained by moving average model only or autoregressive only, Because of this proses consist of both. Therefore, the combination of that two models, is called Autoregressive Integrated Moving Average (ARIMA) model more effectively explain that proses. In this combined model, stationary series is function of previous and present value, present and previous error. General form of this model is:

$$
Y t=b_{0}+b_{1} Y_{t-1}+\ldots+b_{n} Y_{t-n}-a_{1} e_{t-1}-\ldots-a_{n} e_{t-n}+e_{t}
$$

Where :

$\mathrm{Y}_{\mathrm{t}}$ is a stasioner value series,

$\mathrm{Y}_{\mathrm{t}-1 ;} \mathrm{Y}_{\mathrm{t}-2 ;} \mathrm{Y}_{\mathrm{t}-\mathrm{n}}$ are a past value series,

$\mathrm{e}_{\mathrm{t}-1,1} \mathrm{e}_{\mathrm{t}-2 ;} ; \mathrm{e}_{\mathrm{t}-\mathrm{n}}$ are a lag variable of residual,

$\mathrm{e}_{\mathrm{t}}$ is a residual,

$\mathrm{b}_{0}$ is a constant, and

$\mathrm{b}_{1}, \mathrm{~b}_{\mathrm{n} ;} \mathrm{a}_{1} ; \mathrm{a}_{\mathrm{n}}$ are a model coefficient.

\section{Discussion}

The data used in the process of prediction simulating about carbon dioxide emission is based on the carbon dioxide emissions come from the transportation sector, industrial sector and the household sector in Surabaya from 2001 until 2010. The data obtained from Surabaya statistical Office and IESR as shown in Figure 1 (a).

Based on carbon dioxide emission data, then according to data we calculate it and knowing the value of parameters (q, d, p). Based on the parameter value, we used ARIMA $(1,0,1)$ for the prediction of Carbon Dioxide Emission. The next step is held to predict the number of carbon dioxide emissions come from the transportation sector, industry sector, and the household sector in Surabaya. The result of carbon dioxide emission prediction shown in Figure 1 (b).

The result was obtained from the value of carbon dioxide emissions prediction in Surabaya, simultaneously increasing as shown in Figure 1 (a). The results showed that in 2014, transportation sector, industry sector, and household sectors would produce about 55691.79 ton of carbon dioxide emissions and will increase by 2029 to reached about 81416.04 ton of carbon dioxide emission. 
Based on Indonesia Government Regulation no. 26 / 2007 about spatial planning, green open space requires in urban areas at least $30 \%$ of the city area and City Government Regulation about Surabaya spatial city planning (RTRW), the green open space ratio in Surabaya, $20 \%$ of the area is a public green open space and $10 \%$ is a private green open space. If the total area of Surabaya reached 32.637 ha, it means the green open space area at least should be 6527.4 ha and just be able to absorb carbon dioxide emissions by 84372.63 ton. The prediction result shown in 2029 is about 81416.04 ton, it indicates that the green open space in Surabaya is able to absorb the emission is up to 15 years, or until 2030. After 2030, green open space in Surabaya has not been able to absorb the overall carbon dioxide emissions.

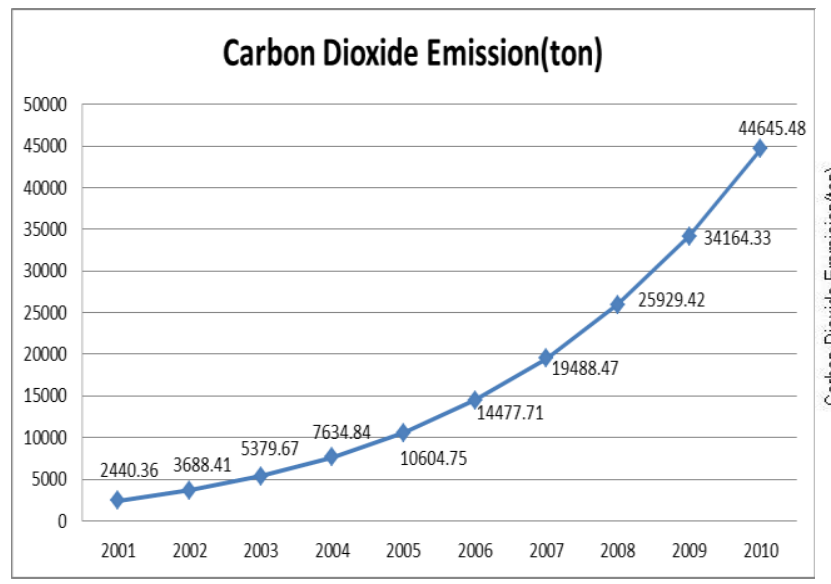

(a)

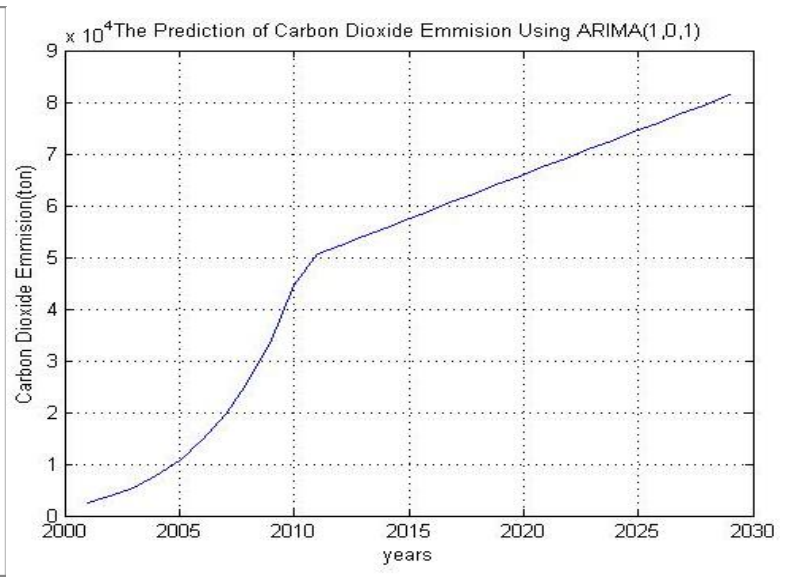

(b)

Fig. 1(a). Carbon Dioxide Emission in Surabaya.

Fig. 1(b). Prediction of Carbon Dioxide Emission in Surabaya.

\section{Conclusions}

Based on the result of the carbon dioxide emission prediction in Surabaya until 2030, known that the carbon dioxide emission growth every years. But the green open space in Surabaya should be $30 \%$ of the city area or about 6527.4 ha and the green open space in Surabaya only absorb carbon dioxide emission about 84372.63 ton per year.

Hence, it needs an action to reduce carbon dioxide emissions with adding the green open space and doing energy conversion from fuel oil into renewable energy that more environmentally friendly and implementing the policy about traffic and public transportation to reduce the number of private vehicles on the street in Surabaya.

\section{Acknowledgements}

Appreciation to DIKTI Republic of Indonesia which has been given an opportunity and a scholarship program and also Appreciation to Sepuluh Nopember Institute of Technology which has been given facilities to Engineering Physic Department.

\section{References}

[1] Kyoto Protocol To The United Nations Framework Convention On Climate Change.1998. 
[2] The Kyoto Protocol Mechanisms. International Emissions Trading Clean Development Mechanism Joint Implementation. 2010.

[3] Institute for Essential Services Reform (IESR). Potensi Penurunan Emisi Indonesia Melalui Perubahan Gaya Hidup Individu. 2011.

[4] Kyoto Protocol Reference. Manual On Accounting Of Emissions And Assigned Amount.2008.

[5] Environmental Department. "Low Carbon Society". SLHD. 2012.

[6] Ruohong Peng. "ICT Solutions Calculation Model for CO2 Emission Reduction and Prediction on its Emission Reduction Potential". IEEE. 2009.

[7] Li Xinwu. "The Effect of Demand Information on Carbon Emission in Low Carbon Green Supply Chain". IEEE. 2012. (Int. Conference on Management of e-Commerce and e-Government).

[8] Jianpeng Zhou. "The Analysis on Carbon Emission Reduction effect of Closed-loop Supply chain Based on Government's Recoverying subsidy". IEEE. 2011. (Fourth Int. Joint Conference on Computional Science and Optization).

[9] Ye Bin. "Pricing Carbon Allowance Based on Marginal Abatement Cost". IEEE. 2012.

[10] Ratri Adiastri. "Kajian Mengenai Kemampuan Ruang Terbuka Hijau (RTH) Dalam Menyerap Emisi Karbon di Surabaya”. ITS. 2010.

[11] Ian G. Enting, Nathan Clisby. "Carbon-climate Measurements Mathematics Modelling". MASCOS. The University of Melbourne. 2007. 